\title{
Editais de Intercâmbio e Difusão Científica: uma Aproximação entre Arte, Ciência e Cotidiano
}

\author{
The Scientific Interchange and Dissemination Calls for \\ Proposals: Ties between Art, Science and Everyday Life
}

\section{RESUMO}

Analisaremos o programa de editais promovido pela Pró-Reitoria de Cultura e Extensão. Na primeira parte do artigo, discutimos as especificidades e pontos de aproximação entre as categorias dos editais, a partir de uma leitura panorâmica da estrutura e orientações conceituais do Programa. Seguimos apresentando projetos contemplados pelo edital de intercâmbio e difusão científica trazendo pontos de contatos entre os mesmos, já ensejados pelo próprio Programa. Finalmente propomos uma leitura do edital de intercâmbio e difusão científica a partir da generalização da presença da arte, ou de meios de criação e exposição artística, no cotidiano e na ciência. Da aproximação da arte e da ciência ao cotidiano, e entre procedimentos e representações produzidas pela arte e ciência levantam-se problemas tratados pela filosofia da estética como o fim da arte, entendido como o fim da especificidade manifesta entre produtos cotidianos e da arte. Andy Warhol, Jonh Cage, Marcel Duchamp, entre outros, são casos exemplares de mudanças no entendimento da arte pela filosofia da estética.

Palavras-chave: Difusão. Cultura. Arte. Intercâmbio.

\section{ABSTRACT}

We will analyze the call for proposals made by the Provost for Culture and Extension. At first we discuss the specificities and ties between each category in the call for proposals, starting from an overview of the program's structure and guidelines. We follow by presenting the selected projects in the Scientific Interchange and Dissemination call, highlighting their points of contact, sparked by the call itself. Finally we propose an interpretation of the call based on a generalization of the presence of art, artistic creation and display means, in daily life and in science. From the approaches between art, science, everyday life and procedures and representations made by art and science we reach problems addressed by the philosophy of aesthetics, like the 
end of art, understood as of the specificity between art and everyday products. Andy Warhol, John Cage, Marcel Duchamp, among others, are exemplary cases of changes in the understanding of art by the philosophy of aesthetics.

Keywords: Culture. Art. Science. Dissemination. Exchange.

INTRODUÇÃO

O objeto deste artigo é o Programa de Editais da Pró-Reitoria de Cultura e Extensão Universitária lançado em 2012, especialmente o de Difusão e Intercâmbio Cultural e Científico. Adotando como pano de fundo uma reflexão sobre a intersecção entre arte e cultura na contemporaneidade, partimos de um exame panorâmico sobre os editais de preservação a fim de problematizar a relação intrínseca entre os três programas. Estes atendem demandas que se completam, e oferecem mais de uma alternativa de investimento para preservação e difusão da produção universitária. A natureza dos acervos, dos agentes envolvidos no processo e os desafios relacionados a "o que", e "como" realizar ações de preservação, traz questões relacionadas à administração, à conservação e à divulgação de conhecimentos, encarnados no patrimônio construído pela Universidade de São Paulo ao longo de décadas.

Se a título da constituição de critérios de avaliação das propostas, fez-se necessária a criação de categorias, a configuração contemporânea das artes, da comunicação e consequentemente da cultura, aponta o imbricamento de problemas e de estratégias de solução dos mesmos, cruzando as categorias. Os editais nominalmente voltados à preservação, trazem pelos menos dois grandes desafios de nossa época. O primeiro relaciona-se à heterogeneidade e quantidade de material a ser guardado e conservado, a como se alocar e disponibilizar dados em diversas formas que se multiplicam exponencialmente. $\mathrm{O}$ segundo coloca em questão a definição de critérios sobre o que deve ser considerado patrimônio e quais as técnicas a serem empregadas visando maximizar a duração do acervo e, por conseguinte, a qualidade do trabalho.

A abrangência e diversidade de arquivos têm gerado uma série de debates e exposições sobre o tema*. Nos deparamos com instigante inversão do lugar do arquivo. $\mathrm{O}$ mesmo deixa de ser um fim, um destino da memória e história de um tempo, e passa a ser um meio de criação de novos produtos, renovando não apenas nas ciências ou humanidades o sentido do material, mas também nas artes. A vida de todo e qualquer

\footnotetext{
*Exemplo de trabalho desenvolvido a partir de arquivos é a exposição Arquivo vivo do Paço das Artes, cujo recorte curatorial, de Priscila Arantes, centrou-se em artistas que se apropriam de arquivos, sejam eles obras primas das artes ou objetos quaisquer. A curadoria de Arantes dialogou com Jacques Derri$\mathrm{da}$, que expressa sua preocupação com o arquivo no trabalho Archive Fever: A Freudian Impression [4] <http://www.pacodasartes.org.br/exposicao/arquivo_vivo.aspx>. A coleção Documents of Contemporary Art da editora inglesa Whitechapel organiza coletâneas sobre temas recorrentes nas artes, um de seus volumes é The Archive (2006). A Edusp e a editora Peirópolis lançaram em 2014 o livro Futuros Possíveis - Arte, museus e arquivos digitais, organizado por Giselle Beiguelman e Ana Gonçalves Magalhães. O mesmo trata de como se preservar a arte digital. Exposições e livros discutem nossa época, marcada pela profusão de documentos e sua duplicação em diversas formas.
} 
acervo se faz no contato com o público. Eventos, documentos e monumentos ganham efetiva existência ao serem disponibilizados nas mais distintas formas. Na difusão, está o encontro do público com a vida dos materiais. A Pró-Reitoria considerou o acesso aos bens materiais e imateriais da Universidade, um dos pilares e objetivos do Edital, ao exigir, uma única contrapartida para apoiar projetos na área de preservação de acervos e patrimônio cultural na USP, "o direito de consulta, pesquisa e visitação aos acervos" pelo público em geral, o que em última instância, implica na difusão dos conteúdos, perspectiva privilegiada no edital de intercâmbio de atividades de cultura e extensão. Evidencia-se o imbricamento das linhas de investimento do Programa e, como mencionamos acima, acervos existem plenamente apenas ao entrar em contato com seu público.

A preservação, genericamente entendida, demanda trabalho constante de historiadores e museólogos. A diversidade das medias e a heterogênea constituição material dos objetos, coloca novos desafios relacionados ao enfrentamento de desgastes de diversas naturezas sofridos pelas coleções. Definições relacionadas às técnicas, plataformas de preservação a serem adotadas e, às prioridades de conservação, exigem saberes e recursos humanos especializados que precisaram ser acionados pela universidade. Pesquisadores de outros países e do mercado participaram em alguns projetos, assim são renovados e revistos procedimentos de conservação e a universidade se atualiza.

$\mathrm{O}$ programa atendeu à comunidade acadêmica como um todo. Aceitou e recebeu propostas de docentes, funcionários e discentes. Sem discriminar a natureza do vínculo institucional do proponente, o programa estruturou-se segundo o primado democrático, capilarizando o poder de decisão sobre as prioridades a serem atendidas. Mobilizaram-se as três categorias funcionais da Universidade em propostas de ação de seu interesse pessoal. Os projetos contemplados, avaliados por comissões mistas, valorizam a capacidade criativa, propositiva e de realização do corpo acadêmico como um todo. Parte da decisão política é partilhada por toda a Universidade.

O seminário Balanço e Perspectivas, organizado pela equipe da Pró-Reitoria de Cultura e Extensão em novembro de 2014, criou um espaço institucional de avaliação conceitual do programa e da resposta da comunidade, expressa nos projetos enviados e contemplados com o incentivo. Os dados levantados poderão servir de baliza para novas edições do programa. Houve ainda espaço para a exposição das dificuldades ocasionadas pelo contingenciamento dos recursos. A Universidade, através da Pró-Reitoria, criou um canal de auto-reflexão sobre os editais, seus caminhos e descaminhos provocados pela crise. $\mathrm{O}$ amplo e diferenciado leque de eventos expositivos, de seminários, de performances, de publicações e de cursos abarcou as áreas de Exatas, Biológicas, Humanidades e Artes.

Gostaríamos de salientar a relevância dos editais como espaço de produção e de renovação do conhecimento. A vida cotidiana da Universidade não pode prescindir da invenção e contato com a comunidade. Mas, corre-se constantemente o risco de questões administrativas, a repetição do ensino e pressões de pesquisa descolarem a vida acadêmica da sociedade. A extensão é o lugar privilegiado para se criarem redes de contato entre o saber formal gestado na Universidade e a comunidade. Para alcançar um público nem sempre informado pelos conceitos e práticas da vida acadêmica, 
novas estratégias de formalização do conhecimento precisam ser adotadas. Para tornar palatável e acessível a produção universitária, evitando-se abordagens simplistas dos conteúdos, a criatividade e a invenção de mecanismos de expressão precisam ser adotados em projetos, novos ou já consolidados, que prevejam o contato com um público não especializado. A Experimentoteca, sob a guarda do Centro de Divulgação Científica e Cultural (CDCC), é um caso exemplar de aproximação criativa com o público. Voltada para professores e alunos do ensino fundamental e médio, restaurou 102 conjuntos de experimentos temáticos nas áreas de matemática, biologia e física. As Faculdades de Economia, Administração e Contabilidade (FEA), de Arquitetura e Urbanismo (FAU), e o Instituto de Arquitetura e Urbanismo (IAU), entre outras, vão recuperar acervos fotográficos e audiovisuais, disponibilizando os mesmos na internet. Há assim, a reordenação do fluxo de informações produzido na universidade e disponibilizado na rede mundial de computadores.

As propostas e ações apresentadas, as concepções e formalização de conhecimento e os agentes envolvidos, traduzem a universalidade dos caminhos possíveis de promoção da educação formal. As propostas encarnam a transversalidade da pesquisa, do ensino e da extensão a partir de projetos do seu corpo funcional. Potências e devires se atualizam, produzindo mais conhecimento ao se reinventarem os conteúdos para um novo público. O conhecido tripé a ancorar a Universidade: ensino, pesquisa e extensão, fica evidenciado na proposta de Manutenção e ampliação da coleção biológica Prof. Edmundo Ferraz Nonato, do Instituto Oceanográfico (Colbio) e, no projeto de difusão Inter-Câmbios: Dramaturgia do ator. O primeiro ampliou o acervo de amostras biológicas marinhas, e os disponibilizou na internet. Recebeu ainda, uma pesquisadora da Califórnia, especialista na área de coleções biológicas. O segundo organizou um intercâmbio entre grupos de pesquisa de Portugal e do Brasil através de workshops, palestras e publicações. Em ambos os exemplos, é evidente a pesquisa na definição dos problemas a serem enfrentados, e na metodologia de trabalho. Atinge-se o pesquisador, especialistas e público diletante, assim, o Edital de preservação também é difusão.

Se as agências de pesquisa avaliam as instituições de ensino superior, a partir da investigação acadêmica, a extensão, raramente tem um reconhecimento que faça jus a seu papel. O Programa de Editais de Extensão evidencia o imbricamento do ensino, pesquisa e extensão. Como produtora de conhecimento, a Universidade de São Paulo está embebida desta matéria, seu capital simbólico e campo de ação. Ao "desenhar um modelo o mais abrangente possível, de modo a permitir acolher não apenas um número maior de propostas, mas também mapear potenciais carências em sua heterogeneidade", como colocou o professor José Lira**, coordenador acadêmico do programa, juntamente com Marina Mitiyo Yamamoto, estão entendendo a fluidez das fronteiras que separam os editais, e acolhendo propostas não previstas pela Pró-Reitoria.

\footnotetext{
**Texto: Patrimônio e Cultura: uma política de fomento em áreas sensíveis, disponibilizado no material preparatório do encontro de avaliação dos editais realizado em novembro de 2014.
} 


\section{DIFUSÃO, INTERCÂMBIO CULTURAL E EXTENSÃO}

Com alcance internacional, o edital de Intercâmbio de Atividades de Cultura e Extensão, estruturou-se segundo as categorias: exposição, artes performativas, música, audiovisual, linguagens híbridas e propostas temáticas, promovendo convênios com deslocamento bilaterais entre a USP e universidades da Polônia, França, Espanha, Bélgica e Portugal na Europa. Nas Américas: México e Chile, e no Brasil: Bahia, Paraná e Rondônia. Os países mencionados foram cabeças de intercâmbios, mas o alcance territorial dos intercâmbios foi além dos países mencionados. Eventos com objetivos variados e envergaduras distintas foram realizados, envolvendo pesquisadores e artistas de diversos países.

O Programa de Pós-Graduação em Artes Cênicas da ECA-USP sediou o $8^{\circ}$ Encontro do Instituto Hemisférico dos Estudos de Perfomance (Performance Studies de Nova Iorque), recebendo entre 400 e 700 participantes, segundo a organização. Trata-se de um encontro acadêmico e artístico editado anualmente, e reconhecido por sua comunidade internacional. Já a Bienal Internacional de Teatro da Universidade de São Paulo recebeu convidados da Tunísia, Líbano, Eslovênia, Argentina, Palestina, Israel e Inglaterra, inscrevendo a universidade no circuito internacional de festivais universitários. O projeto Sinopses de Vários Territórios apresentou outro desenho de intercâmbio e difusão. Proposto pelo Departamento de Artes Plásticas, levou em 2013, para a Escola Superior de Belas-Artes de Tours (ESBAT), na França, a exposição Modernisme et Photographie au Brésil. 1940-196o. Dois grandes fotógrafos brasileiros, Geraldo de Barros e German Lorca, desconhecidos na França, tiveram seu trabalho inovador e criativo estudado e exposto, uma lacuna começou a ser sanada. O projeto Sinopses de Vários Territórios organizou ainda workshops, e intercâmbio de jovens artistas. A partir da fotografia e da escrita, estes tiveram a oportunidade de pensar questões relacionadas à cidade e paisagem, especialmente de Paris e de São Paulo.

Nos projetos citados, e em outros contemplados, mas ainda não mencionados, observam-se abordagens distintas do trabalho de difusão e intercâmbio. De um lado há o incentivo a eventos que promovem encontros de especialistas para o debate de temas variados e apresentação de trabalhos artísticos, é uma espécie de seminário acadêmico ampliado, por incluir eventos artísticos. Outro desenho prevê o intercâmbio criativo, uma vez que os estudantes desenvolvem trabalhos pessoais e a recuperação de nomes e fatos relevantes, mas sem o devido reconhecimento, seja nacional ou internacional. Uma terceira modalidade são as caravanas, e/ou exposições itinerantes. A Escola de Artes, Ciências e Humanidades (EACH) equipou um caminhão com trabalhos científicos viajando para a Universidade Estadual de Santa Cruz (UESC) em Ilhéus, Bahia, e pela zona leste. A apresentação de espetáculos artísticos como música e teatro de professores e alunos, é um núcleo de ações entendido como arte no sentido clássico. O público visado é o especialista na matéria proposta, seja artística ou científica, e ainda o distraído neófito eventualmente atraído ao evento.

As estratégias de promoção do encontro dos trabalhos com o público primaram nas propostas, pelo cuidado na apresentação dos conteúdos. Direta, ou indiretamente, todos lançaram mão da arte, ou suportes da arte, seja como meio, ou como fim. 
Adotaram-se com frequência recursos expressivos e de montagem das exposições, diretamente relacionados a espaços artísticos como galerias e museus ${ }^{* * *}$. O espectador é convidado a vivenciar uma experiência estética, sem outro fim imediato, a não ser o prazer do encontro com as obras. Subjacente a este objetivo sensível imediato, habita a proposta de se trabalhar com conteúdos mais, ou, menos especializados. Mobiliza-se assim a atenção do público. Do encontro marcado pelo prazer e pela curiosidade, apresentam-se ideias e conceitos algumas vezes áridos em instâncias acadêmicas. Os projetos: Atualização do vídeo: Cuidando do Idoso em Casa (Hospital Universitário) e Reconstrução dos Espaços da Memória com famílias de São Luiz do Paraitinga (Instituto de Psicologia) adotaram a arte como meio. Ambos lançaram mão de documentários como recurso de ação.

Poderíamos problematizar se efetivamente ainda estamos no campo do documentário, como entendido pelos estudiosos da área. Trata-se de documentário, de documentação ou apenas uma corruptela do gênero como um trabalho institucional? Se para o expert, esta indagação levanta questões relacionadas a definições de um campo e, de legitimação dos realizadores perante um público especializado, para o senso comum, um amplo leque de criações audiovisuais não encenadas, são entendidas como documentário. Aqui, a imprecisão conceitual do não especialista, é combustível para a fabulação do público. Muito além das definições de área, os "documentários" propostos encurtam caminhos para se atingir novos públicos e despertam o interesse pelo adensamento de informações e formação, por parte do não especialista. Os problemas abordados crescem em interesse.

Já a arte como fim, bastante recorrente neste edital, parte principalmente da Escola de Comunicações e Artes (ECA), espaço da universidade cuja vocação é a constituição de um espaço relacional e de formação, que possibilite a emergência de novas vocações em artes.

O FIM DA ARTE. VIVA A ARTE!

A tão propagada idéia do fim da arte na filosofia estética mostra-se instrumento potente na leitura deste edital, ao se constatar a pervasividade da arte nas estratégias de aproximação com o público. Em linhas gerais, as idéia de Arthur Danto, a partir da releitura de Hegel sobre o "Fim da Arte", traz como problema a ampliação do entendimento da arte nos anos sessenta na filosofia da estética, a partir de movimentos como a Pop Arte, o grupo alemão Fluxus, Jonh Cage e a dança de Merce Cunningham. Para Danto, assim como para o filósofo da estética, Greenberg, a partir destes experimentos, em especial das caixas Brillo de Warhol, a arte torna-se indiscernível dos objetos cotidianos. Se para Hegel o fim da arte relacionava-se ao esgotamento

\footnotetext{
***Têm sido cada vez mais comuns montagens cuidadosas, criadas e produzidas por cenógrafos e designers, de exposições relacionadas a temas diversos. O Museu da Língua Portuguesa é um espaço da cidade de São Paulo reconhecido como tal, malgrado pasteurizar e simplificar em demasia seus conteúdos.
} 
de um modelo de beleza, para Danto e Greenberg, a arte tomará como matéria, objetos, sons e ações cotidianas, "a questão da natureza de fato é posta em sua própria forma, enquanto uma questão sobre como uma coisa pode ser obra de arte e outra não, quando ambas são indiscerníveis em suas propriedades manifestas" [6]. Para Danto a arte havia ido tão longe, em direção ao cotidiano, a ponto de, repetindo-me, tornar-se indiscernível da vida.

Danto adota a Pop Arte como marco privilegiado para se pensar a estética e seu alargamento, mas esta visão da arte já estava posta no dadaísmo, quando objetos do cotidiano produzidos em série ganharam o estatuto de arte a partir das provocações de Marcel Duchamp, o R. Mutt do urinol denominado A Fonte, e recusado em exposição realizada nos Estados Unidos em 1917. Se Danto não enfatiza o papel de Duchamp na renovação da idéia de arte para a filosofia da estética, sua aproximação, ou melhor, o entendimento como indiscernível dos materiais da arte e do cotidiano, chama nossa atenção para o gesto estético (intencional ou não) da grande maioria das propostas do Edital, ao buscarem, na formalização final de suas investigações, projetos marcados pelo cruzamento entre ciência e arte, arte e vida. Se o pensamento sobre o que vem a ser arte, modifica-se com as caixas Brillo****, ou Jonh Cage ao destacar o ruído (da máquina de escrever, de animais, e das ruas) como música, ou matéria da música, de outro lado, cientistas já haviam exposto seus experimentos gozando do estatuto de arte.

Estou me referindo a Edward Muybridge e Jules Marey. Contemporâneos, foram precursores do cinema. Muybridge combinou pela primeira vez elementos da lanterna mágica e do instante fotográfico, foi chamado para Palo Alto, na Stanford University, para fotografar o trote dos cavalos. Marey, no Collège de France, desenvolveu aparelhos, inventados um após o outro, para gravar o coração, o pulso, e finalmente para gravar o movimento dos animais. Todos colocados em papéis em forma de cilindros que se moviam [6]. Experimentaram e desenvolveram, a partir de distintas técnicas, fotografias sequenciais, os primeiros aparelhos a reproduzir o movimento. Marey fisiologista, era da ciência, Muybridge o artista. Hoje, ambos ocupam lugar semelhante na história, apesar do maior rigor nos experimentos de Marey sobre o movimento de pássaros. Sua pesquisa sobre movimento de gases e a resistência do ar a eles, ocupa galerias de arte e, como tal é lida. Didi-Hubermann dedicou um ensaio poético a Marey e sua arte do movimento.

\footnotetext{
****Uma diferença notável entre o trabalho de Duchamp e de Warhol das caixas de sabão Brillo, é a recriação das caixas por Warhol, de madeira e pintadas. Enquanto Duchamp assina o urinol e o nomeia A Fonte.
} 
Figura 1 - Fumaça de Marey (1899-1900).

Figura 2 - À esquerda, máquina para fazer fumaça (1899-1900). À direita, reconstituição de 1999 pela Cinemateca Francesa para exposição Mouvements de l'air, Étienne-Jules Marey, photographe dés fluides, no Museu

d'Orsay.
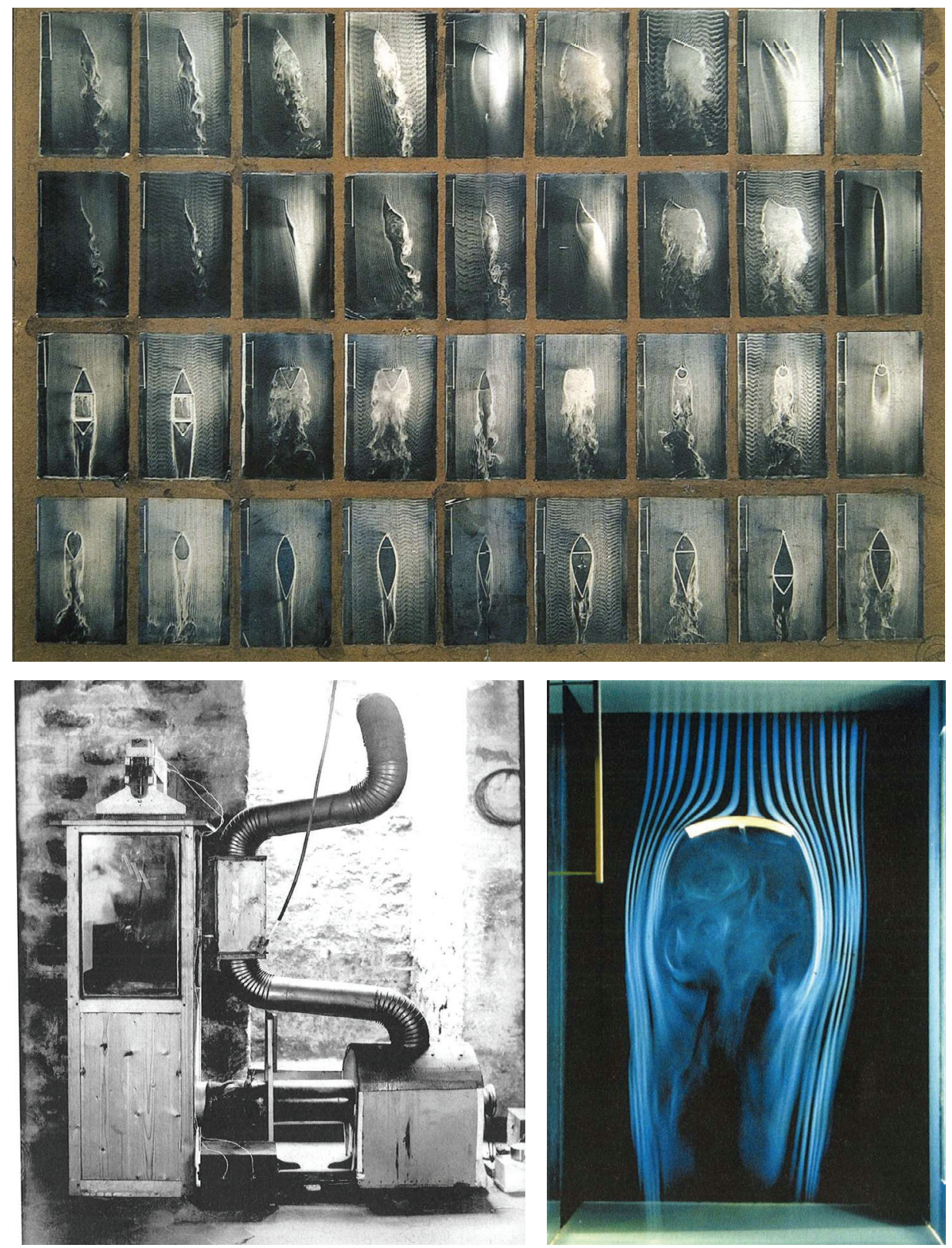

Ao defender uma mudança no pensamento sobre a arte a partir de Warhol, Danto não pensava nas belas formas produzidas por Marey, pelo contrário, era na presença do banal na arte ${ }^{* * * *}$. Quando vejo o edital de Intercâmbio privilegiar procedimentos

*****"O autor do projeto da caixa de Brillo era o artista James Harvey, pintor expressionista abstrato que trabalhava como designer de embalagens"[3]. Irônico destino do artista que vê seu trabalho de designer, sem qualquer pretensão artística, parar em galeria de arte e, segundo alguns autores, mudar o destino da arte, enquanto a obra por ele considerada artística, apaga-se do panteão da história.de de São Paulo reconhecido como tal, malgrado pasteurizar e simplificar em demasia seus conteúdos. 
expositivos e meios de expressão comuns à arte, pergunto-me por que não entender este gesto de aproximação com o público como um recurso de criação tão poderoso quanto algumas obras artísticas. Podemos ir mais longe, e entender o próprio conteúdo como arte, na medida em que também é capaz de suscitar experiências estéticas no sentido tradicional, ou seja, relacionadas às belas formas dos experimentos, e em termos conceituais, como as indagações sensíveis contemporâneas. Hoje, o mais banal programa de televisão, também lança mão de imagens científicas, ou pretensamente científicas, para proporcionar, ao espectador, pequenas epifanias. $\mathrm{O}$ interior do corpo humano constantemente exibido como uma palheta de fluidos e cores, suspende narrativas com formas em evolução. Programação de computadores, linhas de comandos com zeros e uns, são exploradas em seu aspecto plástico. Enfim, a ciência e a arte se reconciliam novamente e a forma final dos eventos apresentados nesta categoria, sinaliza a potência da arte, ou melhor, de formas da arte, para fazer circular culturalmente saberes os mais variados.

\section{REFERÊNCIAS}

[1] BROOKMAN, P. Eadweard Muybridge. London: Tate Publishing, 2011.

[2] DANTO, A. C. O descredenciamento filosófico da arte. Belo Horizonte: Autêntica, 2014.

[3] . Andy Warhol. São Paulo: Cosac Naify, 2012.

[4] DERRIDA, J. Archive Fever: A Freudian Impression Chicago: The University of Chicago Press, 1985[5] DIDI-HUBERMAN, G.; MANNONI, L. Movements de l'air. Étienne-Jules Marey, Photographe des fluides. Paris: Éditions Gallimard / Réunion des musées nationaux, 2004.

[6] GILMORE, J. Prefácio. In: DANTO, A. C. O descredenciamento filosófico da arte. Belo Horizonte: Autêntica, 2014. P. 11-23.

[7] KITTLER, F. Optical Media. Polity Press. Cambridge: UK, 2011.

[8] MAREY, E-J. Le mouvement. Nîmes, Éditions Jacqueline Chambon, 2002.

PATRÍCIA MORAN docente do Curso Superior do Audiovisual da Escola de Comunicações e Artes da Universidade de São Paulo (ECA-USP) e diretora do CINUSP Paulo Emílio - e-mail: patriciamoran@uol.com.br 